\title{
Personal privacy, public benefits, and biobanks: a conjoint analysis of policy priorities and public perceptions
}

\author{
Daryl Pullman, PhD' , Holly Etchegary, $\mathrm{PhD}^{2}$, Katherine Gallagher, $\mathrm{PhD}^{3}$, Kathleen Hodgkinson, PhD', \\ Montgomery Keough, MSc${ }^{1}$, David Morgan, $\mathrm{PhD}^{4}$ and Catherine Street, BPharm ${ }^{1}$
}

\begin{abstract}
Purpose: To assess the public's perception of biobank research and the relative importance they place on concerns for privacy and confidentiality, when compared with other key variables when considering participation in biobank research.
\end{abstract}

Methods: Conjoint analysis of three key attributes (research focus, research beneficiary, and privacy and confidentiality) under conditions of either blanket or specific consent.

Results: Although the majority of our participants described themselves as private individuals, they consistently ranked privacy and confidentiality as the least important of the variables they considered. The potential beneficiary of proposed research ranked the highest under conditions of both blanket and specific consent. When completing the conjoint task under conditions of blanket consent, participants tended to act more altruistically.

Conclusion: The public tends to view biobanks as public goods designed primarily for public benefit. As such it tends to act altruistically with respect to the potential benefits that might accrue from research using biobanked samples. Participants expressed little concern about informational risks (i.e., privacy and confidentiality) should they choose to participate. The manner in which policy priorities are framed could impact participant value preferences with regard to a number of governance issues in biobanking.

Genet Med 2012:14(2):229-235

Key Words: altruism; biobank; conjoint analysis; consent; privacy; public goods

\section{INTRODUCTION}

A biobank can be defined somewhat comprehensively as "any depository of biological samples and related derivatives, with or without a predefined period of storage, based on prospective collection or made up of previously collected material, obtained for health care purposes, public health monitoring programs, or for research, and that includes identified, identifiable, anonymized or anonymous samples." Biobanks, as such, have existed for many decades and in various forms including stored pathology samples, newborn baby heel prick blood spots, medical laboratory samples, and so forth. Nevertheless, the term "biobank" itself is relatively new to the health information lexicon, having first appeared in PubMed in 1996 to refer to large population banks of human tissue and related data collected primarily for the purpose of genetic research. ${ }^{2}$ Recent developments in genetic and information technologies now make it possible to extract and analyze genetic information derived from stored biological specimens and to link this information with existing data sets. In the health sector, biobanks promise new insights and more effective therapies on a wide range of complex diseases. This tremendous research potential has contributed to a veritable explosion of biobanks in countries around the globe in both the public ${ }^{3}$ and private ${ }^{4}$ sectors and a renewed interest in using previously stored samples for research purposes. ${ }^{5}$
Indeed, in 2009, Time Magazine named biobanking as one of the Top 10 Ideas that are changing the world right now. ${ }^{6}$

Despite such enthusiastic predictions about the research benefits to be achieved through the exploitation of biobanked specimens and related information, there is continuing concern that this potential may not be realized any time soon. The problem is a lack of international consensus on appropriate regulatory standards and governance structures for biobanks. ${ }^{7-12}$ This regulatory impasse is perplexing in light of the fact that broad international consensus has been achieved for guidelines related to clinical research in which the risks of direct physical harm to participating individuals are generally much higher than is the case with research on biobanked samples. However, although clinical research guidelines are designed to limit identifiable harms to individual research subjects, research using biobanked specimens is generally directed at populations. The physical risks to individuals who consent to donate a blood sample to a prospective biobank are relatively minor and are virtually nonexistent when the research is on previously stored materials such as pathology samples or blood spots. As such, the standards set to protect individuals in the context of clinical research may be inappropriate for biobanks. ${ }^{13,14}$ This is not to deny that there may be other significant risks associated with biobanks; privacy risks in particular have been singled out as

\footnotetext{
${ }^{1}$ Faculty of Medicine, Memorial University, St. John's, Newfoundland, Canada; ${ }^{2}$ Eastern Health Care Corporation, St. John's, Newfoundland, Canada; ${ }^{3}$ Faculty of Business, Memorial University, St. John's, Newfoundland, Canada; ${ }^{4}$ Newfoundland and Labrador Centre for Health Information, St. John's, Newfoundland, Canada. Correspondence: Daryl Pullman (dpullman@mun.ca) 
worthy of special attention. ${ }^{15}$ However, even such informational risks might be viewed differently from either an individualistic or a public perspective.

Much of the current discussion and debate with respect to appropriate consent and privacy standards for biobanks can be mapped to the aforementioned tension between adopting a clinical versus a population-based model for research ethics and governance. ${ }^{16}$ Indeed, a recent US National Institutes for Health-sponsored study recommends that more research should be conducted to assess whether describing biobanks as a public benefit might influence participants' attitudes on an appropriate consent model. ${ }^{17}$ Irrespective of which model informs research governance, however, if individual members of the public are to contribute biological samples to biobanks and to grant access to their personal health information for the purposes of research, they will need to understand and appreciate what is being asked of them. Conversely, if public health officials and researchers want to convince the public of the importance of research on biobanked specimens and of the responsibility to contribute biological samples for current and future research, they will need to understand where the public's priorities and preferences lie so as to provide assurances that their preferences will be honored and appropriate precautions taken. ${ }^{18}$ Finally, and perhaps most importantly in the near term, given the absence of consensus on an appropriate governance model for biobanks, if research ethics boards (REBs) are tasked with reviewing and approving research protocols that rely on biobanked samples, REBs will need to appreciate the nature of the risks and potential benefits involved, and how the public understands and weighs such risks and benefits.

In this article, we report the results of a conjoint analysis to assess the public's priorities and preferences with respect to potential health-related research using biobanked specimens. A conjoint analysis methodology assumes that individuals seldom if ever decide on preferences with respect to goods and services on the basis of a single characteristic. Rather, any good or service represents a package or bundle of different features or characteristics; each individual decision in turn involves assessing a variety of characteristics and conducting numerous value tradeoffs in determining which package best represents an individual's preferences, all things considered. ${ }^{19,20}$ For example, when assessing whether the public is concerned about the privacy and confidentiality of their health information when participating in research using biobanked specimens, we need to understand how they weigh the value of personal privacy when compared with other attributes or characteristics associated with this type of research. The package of characteristics assessed in this study includes privacy and confidentiality, the nature of the condition being studied (research focus), and who might benefit from the proposed research (research beneficiary). We also assess different consent scenarios (blanket versus specific consent) to determine whether the nature of the consent model assumed by participants when completing the conjoint task affects the manner in which they weigh various packages of characteristics.

\section{MATERIALS AND METHODS}

The project was approved by Memorial University's Interdisciplinary Committee on Ethics in Human Research. All sample selection and recruitment procedures were decided in consultation with a statistician.

\section{Sample selection}

A minimum of 300 participants are required for conjoint analysis without subgroup analyses; this number assumes a margin of error of $\pm 3 \%$ around importance values estimates and a confidence interval of $95 \% .{ }^{19,21} \mathrm{~A}$ list of residential phone numbers was purchased from Canada Select from which a total of 2,737 numbers were randomly selected for recruitment. Trained recruiters contacted people on the list, recruiting a minimum of 40 people for each session with reminder calls 3 days before sessions. A sample of 327 members of the general public was recruited in this manner. Four additional members of the general public asked to participate in the research after hearing about it from a recruited participant and were included. One participant's data were incomplete and were excluded, making the final sample size 330 .

Data collection occurred in January and February 2010 in a medium-sized Eastern Canadian city. The study was run in groups that ranged in size from 20 to 36 participants. Given the relative complexity of the task, we chose this format to provide ample opportunity to ensure participants understood what was required of them. Although instruction was given to the group as a whole, each participant completed the task individually.

Each session began with the viewing of a 7-minute video that explained the purpose of the research and provided information about biobanks and some of the privacy issues associated with using genetic material in health research. The video script included a description of the nature, composition, and function of an REB and emphasized that all health research (including research on biobanked specimens) required REB approval before it could be undertaken. However, the script was neutral with respect to the question of the public versus the private nature of biobanked information and research. Finally, the video outlined the task in which participants would engage. Following the video, a team member reiterated the details of the task being careful to explain the two consent models and the need to complete the task twice under the differing consent scenarios. The consent definitions were prominently displayed throughout the exercise. Participants were given an opportunity to ask questions to ensure they understood how to proceed. Team members were available throughout the session to answer individual questions of clarification if necessary.

\section{The ranking task}

Each participant was given two sets of 12 cards; each card represented a specific research scenario. Cards were color coded to ensure participants ranked each set under the appropriate consent condition. Salient phrases in each scenario were highlighted in order to assist participants to identify subtle differences (see Figure 1). Participants ranked the scenarios of preference for one 
Table 1 Attributes and levels used in ranking task

\begin{tabular}{|c|c|}
\hline Attributes & Levels \\
\hline \multirow[t]{2}{*}{$\begin{array}{l}\text { Privacy and confidentiality: } \\
\text { Your sample ... }\end{array}$} & $\begin{array}{l}\text { 1.... can be traced back to you. } \\
\text { The researchers will have your } \\
\text { name or have access to other } \\
\text { identifying information. }\end{array}$ \\
\hline & $\begin{array}{l}\text { 2. ... cannot be traced back to you. } \\
\text { The researchers will not know } \\
\text { your name nor will they have } \\
\text { access to other identifying } \\
\text { information. }\end{array}$ \\
\hline \multirow[t]{2}{*}{$\begin{array}{l}\text { Research focus: Your sample } \\
\text { will be used to study the role of } \\
\text { genetics in ... }\end{array}$} & $\begin{array}{l}\text { 1. ... a serious illness that is often } \\
\text { stigmatized (e.g., mental } \\
\text { health or a sexually transmitted } \\
\text { infection). }\end{array}$ \\
\hline & $\begin{array}{l}\text { 2. ... a serious illness that is not } \\
\text { usually stigmatized (e.g., heart } \\
\text { disease or multiple sclerosis). }\end{array}$ \\
\hline \multirow[t]{3}{*}{$\begin{array}{l}\text { Research beneficiary: Your sample } \\
\text { will be used in research that ... }\end{array}$} & $\begin{array}{l}\text { 1. ... could improve your own } \\
\text { health. }\end{array}$ \\
\hline & $\begin{array}{l}\text { 2. ... will not affect your own } \\
\text { health, but could improve the } \\
\text { health of people you love. }\end{array}$ \\
\hline & $\begin{array}{l}\text { 3. ... will not affect your own } \\
\text { health, or the health of people } \\
\text { you love, but could improve the } \\
\text { health of others. }\end{array}$ \\
\hline
\end{tabular}

set of cards assuming blanket consent; for the other set of cards, they ranked the same scenarios assuming specific consent.

Blanket consent. You have given a blood sample. Researchers ask you to give them permission to use this sample for a specific research project. They also ask you to give permission to use this sample in other research projects. They will ask your permission only once, not each time they use this sample.

Specific consent. You have given a blood sample. Researchers ask you to give them permission to use this sample for a specific research project. Each time researchers want to use this sample in other research projects, they must ask you for permission.

For both specific consent and blanket consent, all 12 possible combinations of attributes and levels were presented to participants in random order, and participants were told they could complete the task in any order they wished (i.e., it did not matter whether participants completed the task first assuming blanket consent and then again assuming specific consent or in the reverse order). Each set of 12 cards was randomized separately, so that the order in which the scenarios appeared differed with each set.

Table 1 lists the attributes and levels used to create the scenario cards. From these three attributes, there were $2 \times 2 \times 3=12$ possible combinations of levels, creating 12 unique scenarios to be ranked of preference. In total, participants ranked 24 cards: 12 under the condition of blanket consent and 12 under the condition of specific consent.
After finishing the ranking task, participants completed a short questionnaire that included demographic items and relevant attitudinal and opinion items. At the end of the session, participants were compensated with $\$ 50$ cash for their time and effort.

\section{Data analysis}

The conjoint analysis was performed using the "conjoint" procedure in SPSS 17 (SPSS, Chicago, IL). Through a series of linear regressions, SPSS conjoint uses the ranking of scenarios from each participant to generate utility scores for each attribute level. Utility scores represent participant preferences for that attribute level, with higher utility scores indicating greater preference. The relative importance of each attribute as a whole was also calculated in percentage terms. SPSS computed the importance score by taking the range of utility scores for any attribute level (highest minus lowest), dividing by the sum of all the utility ranges and multiplying by 100 . Thus, SPSS conjoint provided two key pieces of information: (1) the relative importance of each attribute as a whole and (2) the preferences for each of the attribute levels.

\section{RESULTS}

We present descriptive statistics of the sample, followed by the conjoint analyses of card rankings for blanket and specific consent.

The study population was approximately a 60:40 split favoring females $(63.3 \%)$. There was a range of educational backgrounds with $15 \%$ having a high school education or less and $33 \%$ having a bachelor's degree or higher. Almost 50\% indicated that they had attended trade school or had completed some university. The mean age of the sample was 50.8 years $(\mathrm{SD}=13.8)$, and participants had an average of 1.8 children $(\mathrm{SD}=1.4)$. Table 2 provides additional data about the study sample.

The majority of participants regarded themselves as private or very private persons (54\%), although almost one quarter (24\%) classified themselves as open or very open. Respondents reported a high level of trust in health researchers. The nature of the disease being studied was chosen as the most important criterion to consider in making the decision to provide a blood sample for health research (chosen by $32 \%$ of the sample). In comparison, the confidentiality of the sample was chosen by only $17 \%$ of participants. This item is revealing as it included attributes beyond the type of diseases on which we focused in the conjoint analysis (stigmatized versus nonstigmatized diseases). Thus, it reveals additional factors that may be important to the public in determining their attitudes about biobanks for health research.

Tables 3 and 4 list the results of the conjoint analysis for blanket and specific consent respectively. We note that it was not our intention to test formal statistical hypotheses about the utility estimates, for we had no a priori hypotheses about whether and which attributes might be important under the two consent conditions. However, we do present a descriptive 
Table 2 Participant responses to attitudinal and opinion survey items $(N=330)$

\begin{tabular}{|c|c|c|}
\hline Variables & Level & Number (\%) \\
\hline \multirow{5}{*}{$\begin{array}{l}\text { In general, how private a person } \\
\text { would you say you are? }\end{array}$} & Very private & $38(12)$ \\
\hline & Private & $137(42)$ \\
\hline & $\begin{array}{l}\text { Neither private nor } \\
\text { open }\end{array}$ & $70(21)$ \\
\hline & Open & $70(21)$ \\
\hline & Very open & $11(3)$ \\
\hline \multirow{4}{*}{$\begin{array}{l}\text { Overall, how much would you } \\
\text { say you trust health researchers? }\end{array}$} & Completely & $106(32)$ \\
\hline & Somewhat & $206(62)$ \\
\hline & A little & $9(3)$ \\
\hline & Not at all & $5(1)$ \\
\hline \multirow{6}{*}{$\begin{array}{l}\text { Can you tell us the no. } 1 \text { thing } \\
\text { you would want to know before } \\
\text { giving a blood sample for health } \\
\text { research } \\
\text { (please choose one)? }\end{array}$} & $\begin{array}{l}\text { What disease is } \\
\text { being studied? }\end{array}$ & $106(32)$ \\
\hline & $\begin{array}{l}\text { Who is doing the } \\
\text { research? }\end{array}$ & $29(9)$ \\
\hline & $\begin{array}{l}\text { Will I get the } \\
\text { results? }\end{array}$ & $67(21)$ \\
\hline & What are the risks? & $47(14)$ \\
\hline & $\begin{array}{l}\text { Can someone } \\
\text { other than the } \\
\text { researchers identify } \\
\text { me? }\end{array}$ & $58(17)$ \\
\hline & $\begin{array}{l}\text { Other (e.g., "can } \\
\text { I help someone," } \\
\text { "moral," "I am } \\
\text { against for-profit } \\
\text { health research," } \\
\text { and "some good } \\
\text { may result") }\end{array}$ & $10(3)$ \\
\hline
\end{tabular}

aTotals may not add to 100 due to rounding or missing data.

account of what attributes and levels appeared important to participants as they consider two different consent models and consider giving a sample of their DNA to health research. There are two notable pieces of information in the tables: The first is utility scores that represent participant preferences for an attribute level, with higher utility scores indicating greater preference. The second is the relative importance of each attribute as a whole.

For example, under the condition of blanket consent, the most important factor pertained to who could potentially benefit from the research (58.3\%). Both the research beneficiary and the research focus (stigmatized versus nonstigmatized diseases) were ranked more highly than the privacy and confidentiality of the sample.

As revealed by the highest utility estimate (0.232), research that had the potential to benefit others, rather than research that benefited participants themselves or their loved ones, was the most preferred.
Table 3 Results of conjoint analysis: blanket consent

\begin{tabular}{llccc} 
Attribute & Level & $\begin{array}{c}\text { Utility } \\
\text { estimate }\end{array}$ & $\begin{array}{c}\text { Standard } \\
\text { error }\end{array}$ & $\begin{array}{c}\text { Importance } \\
\text { values (\%) }\end{array}$ \\
\hline $\begin{array}{l}\text { Privacy and } \\
\text { confidentiality }\end{array}$ & Can be traced & 0.154 & 0.408 & 19.5 \\
& $\begin{array}{l}\text { Cannot be } \\
\text { traced }\end{array}$ & -0.154 & 0.408 & \\
\hline Research focus & $\begin{array}{l}\text { Stigmatized } \\
\text { Research }\end{array}$ & -0.044 & 0.408 & 22.1 \\
beneficiary & Self & -0.381 & 0.577 & 58.3 \\
& Loved ones & 0.149 & 0.577 & \\
& Others & 0.232 & 0.577 & \\
& (Constant) & 6.5 & 0.408 & \\
\hline
\end{tabular}

Table 4 Results of conjoint analysis: specific consent

\begin{tabular}{llccc} 
Attribute & Level & $\begin{array}{c}\text { Utility } \\
\text { estimate }\end{array}$ & $\begin{array}{c}\text { Standard } \\
\text { error }\end{array}$ & $\begin{array}{c}\text { Importance } \\
\text { values (\%) }\end{array}$ \\
\hline $\begin{array}{l}\text { Privacy and } \\
\text { confidentiality }\end{array}$ & Can be traced & 0.020 & 0.318 & 16.6 \\
& $\begin{array}{l}\text { Cannot be } \\
\text { traced }\end{array}$ & -0.020 & 0.318 & \\
$\begin{array}{llccc}\text { Research } \\
\text { focus }\end{array}$ & Stigmatized & 0.521 & 0.318 & 29.3 \\
& Nonstigmatized & -0.521 & 0.318 & \\
$\begin{array}{l}\text { Research } \\
\text { beneficiary }\end{array}$ & Self & -0.488 & 0.449 & 54.1 \\
& Loved ones & 0.635 & 0.449 & \\
& $\begin{array}{l}\text { Others } \\
\text { (Constant) }\end{array}$ & -0.146 & 0.449 & \\
& & 6.5 & 0.318 & \\
\hline
\end{tabular}

Turning to the results for specific consent, there were not only similarities but also notable differences. The pattern of importance values for the three attributes was similar in that the beneficiary of the research continued to be most important (54.1\%), whereas privacy and confidentiality continued to be ranked as least important (16.6\%).

Inspection of the utility estimates, however, revealed that under the situation of specific consent, the disease on which the research was focused was more important than under the situation of blanket consent. In particular, participants ranked more highly research focused on stigmatized diseases. Notably, although the research beneficiary continued to have the highest utility estimates, under specific consent, the most preferred scenario is research that benefits loved ones, rather than self or others.

\section{DISCUSSION}

Much political, ethical, and academic debate has focused on the protection of personal health information in biobanks and on appropriate models of consent in light of this concern. ${ }^{15,17,22,23}$ As noted at the outset, there is still no consensus on these issues, and if anything, opposing positions seem to be ever more firmly entrenched. ${ }^{9,13,18,24,25}$ 
Although the majority (54\%) of our sample described themselves as either private or very private individuals, and only $24 \%$ viewed themselves as "open," our findings suggest that the public is much less concerned about privacy and confidentiality with respect to their biobanked samples and more concerned about who could potentially benefit from the research and the types of diseases that will be studied. Although the importance values of the three attributes we measured varied somewhat under blanket and specific consent, the overall pattern was similar. For both types of consent, the potential research beneficiary was ranked as the most important factor, whereas privacy and confidentiality of the sample were consistently the least important.

Although the pattern of attribute importance was similar, there were some notable differences. As reflected in the importance values and the utility estimates, the research focus was ranked more highly under specific consent. In particular, when participants were asked to give specific consent for any research project involving their blood sample, they demonstrated a higher preference for research that focused on stigmatized (e.g., mental health) versus nonstigmatized (e.g., multiple sclerosis) diseases. Interestingly, under the situation of specific consent, participants indicated that they preferred research that would benefit their loved ones, rather than others or themselves. This is in contrast to their expressed preferences under the situation of blanket consent where the strongest preference was for research that would benefit unknown others, rather than either themselves or their loved ones.

We are intrigued by the manner in which the nature of the consent model assumed by the participants seems to alter their value preferences. That is, when participants completed the task assuming blanket consent, they displayed more altruistic tendencies, favoring scenarios that would benefit the general public over those that might favor themselves or their loved ones. On the other hand, when asked to assume specific consent, participants preferred scenarios that would favor their loved ones. It may be that specific consent is perceived to be more onerous than onetime, blanket consent. As such, participants want their loved ones rather than unknown others to benefit as a result of the time and effort they must invest to provide repeated consent.

A similar explanation might apply as to why stigmatized diseases are valued more highly under the situation of specific consent. In this case, the utility estimate was much higher $(0.521)$ than in the situation of blanket consent $(-0.044)$, revealing a considerable difference in perceived importance. We speculate that participants reasoned that if they are going to be approached to give consent each time a new project is proposed, the condition being studied should be important enough to them personally to warrant the additional time and effort they must invest to provide specific consent.

Privacy and confidentiality are often presented as key considerations, particularly as this pertains to worries about genetic discrimination. ${ }^{17,22}$ Irrespective of which consent model was assumed, our results indicate that our participants would generally act as "health-information altruists" 26 when considering their participation in biobank research. That is, whether they considered participation from the perspective of blanket or specific consent, concerns about privacy and confidentiality ranked lowest among the attributes they were asked to consider.

Although the public consultation literature assumes that individual preferences will affect policy priorities, our results seem to show the contrary. That is, rather than value preferences influencing policy priorities, the policy option our respondents were asked to assume with respect to blanket or specific consent seemed to influence their value preferences in particular situations. Although our results are preliminary and require further investigation, they may help to explain some of the variation that occurs in the public consultation literature with respect to biobanks more generally ${ }^{27}$ and could provide instruction on appropriate consent processes for population biobanks.

Much is at stake with respect to the consent model adopted for biobank or otherwise, as an overly restrictive consent process could effectively curtail access to valuable data. Clearly, respect for autonomy requires that those invited to participate in any research, biobank or otherwise, understand and appreciate the nature and degree of risk their involvement might entail, as well as the potential benefits (personal and/or public) that could accrue as a result of their participation. Research using biobanked samples does not present the same kind or degree of physical risks as do clinical trials, nor does it offer the same degree of personal benefit. Although the informational risks associated with biobanked data should not be dismissed as insignificant, such risks are generally associated with the manner in which all data in a given biobank is collected, stored, and shared, rather than with how data pertaining to a specific project are managed. The benefits of such research in turn accrue not to individual participants as such but rather to the broader public. Our results indicate that our respondents generally understand and appreciate these aspects of the research that would be conducted with their biobanked information and samples.

Although the majority of our participants considered themselves to be private or very private individuals, they nevertheless consistently judged privacy concerns to be less important than other considerations when expressing their preferences with respect to research using biobanked information. In short, they tended to display a reasonable level of confidence in the governance structure related to biobanked information in general and with respect to the manner in which their privacy and confidentiality would be protected in particular. These findings concur with a recent Scottish study, which indicates that individual's decisions about whether to participate in biobank research are driven by considerations other than those related to the governance structure of biobanks. ${ }^{20}$

Finally, it is worth noting that our study was conducted in Canada where all citizens enjoy access to a publicly funded healthcare system and thus generally express fewer concerns about privacy and confidentiality as it pertains to issues such as genetic discrimination. ${ }^{28}$ This might explain in part the lower priority our participants gave to privacy concerns in this regard. 
However, recent studies from the United States ${ }^{17,22}$ where concerns about genetic discrimination have resulted in significant legislative initiatives at both the state and federal levels indicate that even there respondents generally view privacy risks as of lesser importance than other considerations when contemplating participation in biobank research. Indeed, one calls for more research to determine to what extent "describing biobank collections as a public good in trust for public benefit might influence participants' willingness to accept a broad consent model. ${ }^{17}$ Our results indicate that people may already be inclined to think of research involving biobanks in this manner and that a broad consent model simply serves to enhance that perception.

\section{Limitations}

The nature of the task participants must complete in a conjoint analysis limits the number of levels and attributes that can be assessed in any given study, as each additional attribute multiplies the number of scenarios participants must evaluate and rank. For example, had we included one additional level in this study with respect to the disposition of participant's sample in the case of death, with the options of (i) retaining the sample in the biobank or (ii) destroying the sample, the participants would have been presented with 48 scenarios to rank (24 each under blanket and specific consent, respectively). Although fractional factorial design $s^{29}$ are used at times to reduce an excessive number of scenarios to a manageable number, we opted instead to limit the number of attributes from the outset to keep the number of scenarios at 12 (or 24, when the respondents completed the task under both blanket and specific consent). In so doing, however, we did not address other issues that are commonly discussed in the literature including commercialization, benefit sharing, disposition of samples after death, and so forth. We anticipated that our respondents would not be familiar with the nature of biobanks in general and with the broad range of governance issues associated with their development and implementation. Given the limited time available to provide sufficient background information to our participants before performing the ranking task, we opted for a lower number of attributes. Although we believe we have gained important insights about our participant's preferences and how those preferences are influenced with respect to these particular features of biobank governance, numerous other issues were not canvassed in this study, and the inclusion of such may have affected the rankings of these other preferences as well. In addition to limiting the number of scenarios participants ranked, we also chose to allow them to complete rankings in whatever order they preferred (e.g., completing rankings for blanket or specific consent first). Although we have no reason to suspect that the order in which the rankings were completed would unduly influence which attributes were most important in participants' decision to contribute to health research, we cannot formally test for order effects.

\section{CONCLUSION}

As biobanking initiatives continue around the globe, the utility of these vast repositories of biological samples and related data will be contingent on the willingness of the public to donate their samples and related data, and the ability of researchers to access them. Our findings support a position for which others have argued: biobanks should be thought of generally as a public good to be used for the public benefit. ${ }^{14,30,31}$ Given the relatively minor physical risks involved, policies that require specific consent for each new study are generally unwarranted. Furthermore, our findings suggest that specific consent policies could serve to skew participant's perceptions, such that they might perceive greater individual risks and individual benefits than is otherwise warranted by the nature of the research. This latter is only suggested by our results, however, and warrants further investigation. Nonetheless, current results are useful as they demonstrate it is possible to engage the general public on the complex challenges posed by biobanks. Specifically, these findings suggest that the public is already inclined to view biobanks as a public good and as such are not as concerned about their individual privacy as they are about the focus of the research and with the potential beneficiaries. These results might assist health REBs to tailor the nature and scope of the information potential participants in biobanks should receive when deciding whether to participate in biobank research. In general, our results support a model of broad if not blanket consent with the understanding that an REB will continue to monitor ongoing research activities.

\section{ACKNOWLEDGMENTS}

This study was supported under the "Contributions Program" of the Office of the Privacy Commissioner of Canada.

\section{DISCLOSURE}

The authors declare no conflict of interest.

\section{REFERENCES}

1. Portuguese Law (Law no. 12/2005, January 26, article 19, no. 1). http:// www.privileged.group.shef.ac.uk/projstages/stage1/introduction/ biobankdefs. Accessed 7 September 2010

2. Loft S, Poulsen HE. Cancer risk and oxidative DNA damage in man. J Mol Med 1996;74:297-312.

3. http://www.p3g.org/. Accessed 7 September 2010.

4. Check Hayden E. Major biobank launches in America. Nature 17 December 2008; doi.10.1038/news.2008.1315.

5. Hollegaard MV, Grauholm J, Børglum A, et al. Genome-wide scans using archived neonatal dried blood spot samples. BMC Genomics 2009;10:297.

6. http://www.time.com/time/specials/packages/0,28757,1884779,00.html Accessed 7 September 2010.

7. Knoppers BM. Biobanking: international norms. J Law Med Ethics 2005;33:7-14

8. Elger BS, Caplan AL. Consent and anonymization in research involving biobanks. EMBO Rep 2006;7:661-666.

9. Caulfield T, Kaye J. Broad consent in biobanking: reflections on seemingly insurmountable dilemmas. Med Law Int 2009;10:85-100.

10. Tassé AM, Budin-Ljøsne I, Knoppers BM, Harris JR. Retrospective access to data: the ENGAGE consent experience. Eur J Hum Genet 2010;18:741-745

11. Hoeyer K, Olofsson BO, Mjörndal T, Lynöe N. The ethics of research using biobanks: reason to question the importance attributed to informed consent. Arch Intern Med 2005;165:97-100.

12. Hansson MG, Dillner J, Bartram CR, Carlson JA, Helgesson G. Should donors be allowed to give broad consent to future biobank research? Lancet Oncol 2006;7:266-269 
13. Chadwick R, Berg K. Solidarity and equity: new ethical frameworks for genetic databases. Nat Rev Genet 2001;2:318-321.

14. Knoppers BM, Leroux $T$, Doucet $H$, et al. Framing genomics, public health research and policy: points to consider. Public Health Genomics 2010;13:224-234.

15. Ursin $L \varnothing$. Biobank research and the right to privacy. Theor Med Bioeth 2008;29:267-285.

16. Mullen $C$. Decisions, consent and expectations of the individual. In: Widdows H, Mullen C (eds). The Governance of Genetic Information. Cambridge University Press: Cambridge, UK, 2009:51-72.

17. Murphy J, Scott J, Kaufman D, Geller G, Leroy L, Hudson K. Public perceptions on informed consent for biobanking. Health Policy Ethics 2009;99:2128-2134.

18. Hansson MG. Ethics and biobanks. Br J Cancer 2009;100:8-12.

19. Ryan M, Bate A, Eastmond CJ, Ludbrook A. Use of discrete choice experiments to elicit preferences. Qual Health Care 2001;10(suppl 1): i55-i60.

20. Haddow G, Cunningham-Burley S, Murray L. Can the governance of a population genetic data bank effect recruitment? Evidence from the public consultation of Generation Scotland. Public Understanding Sci 2010;1:1-13.

21. Orme B. Sample size issue for conjoint analysis studies. Sawtooth software, 2010. http://www.sawtoothsoftware.com. Accessed 7 September 2010 .

22. Kaufman DJ, Murphy-Bollinger J, Scott J, Hudson KL. Public opinion about the importance of privacy in biobank research. Am J Hum Genet 2009;85:643-654
23. Caulfield T, Knoppers B-M. Consent, privacy and research biobanks. Policy brief no. 1. Genome Canada, 2009. http://www.genomecanada. ca/medias/pdf/en/GPS-Policy-Directions-Brief.pdf. Accessed 7 September 2010.

24. Eriksson S, Helgesson G. Potential harms, anonymization, and the right to withdraw consent to biobank research. Eur J Hum Genet 2005;13: 1071-1076.

25. Hofman B. Broadening consent-and diluting ethics? J Med Ethics 2009;35:125-129.

26. Kohane IS, Altman RB. Health-information altruists-a potentially critical resource. N Engl J Med 2005;353:2074-2077.

27. Caulfield T. Biobanks and blanket consent: the proper place for the public good and public perception rationales. Kings Law J 2007;18: 209-226.

28. Pullman D, Lemmens T. Keeping the GINA in the bottle: assessing the current need for genetic non-discrimination legislation in Canada. Open Med 2010;4.2:E95. http://www.openmedicine.ca/article/view/339/ 331 Accessed 7 September 2010.

29. Viney R, Lancsar E, Louviere J. Discrete choice experiments to measure consumer preferences for health and healthcare. Expert Rev Pharmacoecon Outcomes Res 2002;2:319-326.

30. Mladovsky P, Mossialos E, McKee M. Improving access to research data in Europe. BMJ 2008;336:287-288.

31. Academy of Medical Sciences. Personal Data for Public Good: Using Health Information for Medical Research. Academy of Medical Sciences: United Kingdom, 2006. http://www.acmedsci.ac.uk. Accessed 7 September 2010. 